\section{International Scientific Journal Theoretical \& Applied Science}

p-ISSN: 2308-4944 (print) e-ISSN: 2409-0085 (online)

Year: $2015 \quad$ Issue: 02 Volume: 22

Published: 28.02.2015 http://www.T-Science.org
Santay Azizbekovna Tleubayeva candidate of economic science, trainee Moscow State University named after M.V. Lomonosov, Russia ms.santay@mail.ru

SECTION 31. Economic research, finance, innovation, risk management.

\title{
THE ORGANIZATION OF ACCOUNTING AND ANALYTICAL PROCEDURES IN ORDER TO DETECT FRAUD
}

Abstract: This article addresses issues formation of analytical procedures and existing methodological approaches to the detection of fraud through financial investigations. By improving the accounting and analytical procedures available methods for assessing the financial information to commit in the organization of fraud. In the work attention is focused on issue of the application of analytical procedures, including the equation of $M$-score Behnisch.

Key words: accounting and analytical support, fraud, forensic, financial investigation.

Language: Russian

Citation: Tleubayeva SA (2015) THE ORGANIZATION OF ACCOUNTING AND ANALYTICAL PROCEDURES IN ORDER TO DETECT FRAUD. ISJ Theoretical \& Applied Science 02 (22): 41-47. doi: http://dx.doi.org/10.15863/TAS.2015.02.22.9

\section{ОРГАНИЗАЦИЯ УЧЕТНО-АНАЛИТИЧЕСКИХ ПРОЦЕДУР С ЦЕЛЬЮ ОБНАРУЖЕНИЯ МОШЕННИЧЕСВА}

Аннотация: В данной статье рассматриваются вопросы формирования аналитических процедур и действующие методические подходы к обнаружению фактов моченничества с помощью финансовых расследований. Путем совериенствования учетно-аналитических проиедур предлагаются методы оиенки финансовой информации о совершении в организации мошеннических действий. В работе акцентируется внимание на вопросе применения аналитических процедур, в том числе уравнение М-sсоге Бениша.

Ключевые слова: учетно-аналитические прочедуры, моченничество, форензик, финансовые расследования.

С внедрением современных технологий в нашу жизнь постепенно входит понятие «форензик», потому что развитие экономических отношений увеличило негативный рост числа случаев финансового мошенничества, хищений материальной и интелекуальной собственности. И это новое направление услуг по расследованию финансовых махинаций и мошенничества используется для проведения расследований и оказания помощи клиентам в установлении фактов и причин мошенничества, а также поиска похищенных активов компании до крупномасштабных махинаций.

Фактически форензик уже присутствует в многочисленных публикациях в периодической печати, электронных средствах массовой информации зарубежных стран. Еще до начала XXI века, более 30 лет назад в США,
Великобритании и других странах появились консультанты форензик (forensic) [1].

Однако нормативно этот термин четко не определен ни законодательно, ни наукой. Эта ситуация создает неопределенность в понимании сущности и содержания финансового расследования. Теория и практики работы системы внутренних финансовых расследований позволяют рассматривать ее как систему контроля, организованную в интересах собственников и руководителей организации и регламентируемую внутренними документами. Учитывая многообразие определений и критериев классификации контроля, которое предлагают в своих работах ученые, мы опираемся в своем исследовании на категорию «форензик». Процесс, проводимый с целью предотвращения проблем, связанных с 
посягательством на имущество компании и его ненадлежащим использованием, а также сбор доказательств по уже случившимся фактам, называют финансовым расследованием (financial Investigation, forensic Accounting или просто forensic). Форензик - это всестороннее изучение финансово-хозяйственной деятельности компании, направленное на выявление мошенничества, неправомерных или злонамеренных действий как ее персонала всех уровней, так и третьих лиц, являющихся контрагентами [2]. Это процесс, организованный и осуществляемый клиентами для обеспечения достаточной уверенности в достижении целей компании: достоверности надежности финансовой отчетности; рационального использования ресурсов; сохранности активов; управление рисками; предотвращение мошенничества.

Изначально слово «мошенничество» означало «обманное, ловкое хищение чужого имущества» [3]. Первое законодательное определение мошенничества, близкое к современному, было дано в Указе Екатерины II от 3 апреля 1781 года «О разных видах воровства и какие за них наказания чинит»: «Будь кто на торгу... из кармана что вынет... или внезапно что отымет., или обманом или вымыслом продаст, или весом обвесит, или мерою обмерит, или что подобное обманом или вымыслом себе ему не принадлежащее, без воли и согласия того, чьё оно» [4].

Согласно действующему уголовному законодательству России, мошенничество можно определить как «совершенные с корыстной целью путем обмана или злоупотребления доверием противоправные безвозмездное изъятие и (или) обращение чужого имущества в пользу виновного или других лиц, причинившее ущерб собственнику или иному владельцу этого имущества, либо совершенные теми же способами противоправное и безвозмездное приобретение права на чужое имущество» [5].

Мошенники - элита преступного мира - это люди, обладающие высоким интеллектом и определенными познаниями в психологии.

Они обладают умением вступать в контакт, располагать к себе. Они также часто являются специалистами в экономике, информационных технологиях и тому подобное.
Статья 159 УК РФ гласит, что мошенничество - хищение чужого имущества или приобретение права на чужое имущество путём обмана или злоупотребления доверием.

По данным всемирного обзора экономических преступлений для большинства категорий мошенничества статистика по России схожа с данными в целом по миру. Например, самым распространенным видом мошенничества является незаконное присвоение имущества (активов).

Незаконное присвоение активов во все времена являлось наиболее распространенной формой экономического преступления. В то же время, в отношении взяточничества и коррупции, статистика прямо противоположная. Серьезную проблему для российских компаний по-прежнему представляют взяточничество и коррупция. Например, 58\% российских респондентов признали тот факт, что они сталкивались с проявлениями взяточничества и коррупции, в целом по миру этот процент составляет $27 \%$. Значит, эта цифра вдвое превосходит средний мировой показатель и наглядно демонстрирует, какая трудная задача стоит перед российским правительством и бизнесом в деле борьбы с коррупцией.

В 2014 году более распространенными становятся такие виды мошенничества, как киберпреступления по России и по всему миру$25 \%$ и $24 \%$, и искажение финансовой отчетности (манипуляция данными бухгалтерского учета), соответственно - $25 \%$ и 22\%. Значительное увеличение преступлений этого типа можно объяснить сбоями в системе контроля, которые происходят в результате сокращения затрат [6].

Согласно данным исследования транснациональной аудиторской компании PricewaterhouseCoopers (PwC) «Всемирный обзор экономических преступлений» (The Global Economic Crime Survey) в 2011 году показатель «манипулирование данными отчетности» занимал третье место в общей структуре экономических преступлений как в мире, так и в России [7]. Причем данные по РФ находятся в рамках мирового тренда в данном направлении: в мире $-24 \%$ и в РФ $-23 \%$.

Если сравнить данные распространённых форм экономических преступлений с 2014 годом, то замечаем снижение незаконных присвоении активов и увеличение по направлению взяточничества и коррупции (таблица 1). 
Наиболее распространённые формы экономических преступлений, (\%)

\begin{tabular}{|l|l|l|l|l|l|}
\hline № & Виды & $\begin{array}{l}\text { По всему } \\
\text { миру за 2014 } \\
\text { год }\end{array}$ & $\begin{array}{l}\text { Россия 3a } \\
2014 \text { год }\end{array}$ & $\begin{array}{l}\text { По всему } \\
\text { миру за } \\
2011 \text { год }\end{array}$ & $\begin{array}{l}\text { Россия за } \\
\text { 2011 год }\end{array}$ \\
\hline 1 & Незаконное присвоение активов & 69 & 69 & 72 & 72 \\
\hline 2 & Взяточничество и коррупция & 27 & 58 & 24 & 42 \\
\hline 3 & Киберпреступность & 24 & 25 & 24 & 23 \\
\hline 4 & $\begin{array}{l}\text { Манипулирование } \\
\text { бухгалтерского учета }\end{array}$ & 22 & 23 & 23 \\
\hline 5 & Недобросовестная конкуренция данными & нет данных & нет данных & 7 & 17 \\
\hline 6 & $\begin{array}{l}\text { Нарушение прав интеллектуальной } \\
\text { собственности }\end{array}$ & нет данных & нет данных & 7 & 13 \\
\hline
\end{tabular}

При этом не стоит забывать и про нефинансовые потери от экономических преступлений. Сюда относится ущерб, наносимый бренду компании; потеря или снижение доверия потребителей, рынка и акционеров; ущерб, причиненный взаимоотношениям компании с партнерами по бизнесу и с регулирующими органами; ухудшение морально-психологического климата в коллективе, что может привести к высокой текучести кадров и снижению производительности труда. Рост негативного влияния экономической преступности на морально-психологический климат в коллективе может быть связан с общей тенденцией повышения прозрачности бизнеса и усиления нетерпимости бизнес-сообщества к проявлениям коррупции, так как более строгое и нетерпимое отношение компании к противоправным действиям формирует соответствующий моральный посыл для сотрудников. Ниже представлен процент респондентов, утверждающих, что экономические преступления оказывают существенное негативное воздействие на следующие аспекты их деятельности.

Несмотря на то, что нефинансовые потери от мошеннических действий бывает трудно выразить количественно, они могут представлять собой значительные потери для бизнеса. 31\% респондентов в России и $27 \%$ по всему миру утверждают, что экономические преступления, с которыми они столкнулись, оказали существенное негативное воздействие на моральный климат среди их сотрудников.

В 2014 году 16\% компаний сообщили о том, что они стали жертвами экономических преступлений, вследствие которых они понесли прямые финансовые потери в размере свыше 1 миллиона долларов США, что существенно превышает показатели по миру в целом (12\%). Это свидетельствует о том, что ущерб от мошенничества по-прежнему велик.

В то же время мы видим, что случаи с чрезвычайно высокими потерями (свыше 100 миллионов долларов США) происходят все реже. Несмотря на то, что в 2014 году лишь $3 \%$ респондентов столкнулись с такими высокими потерями, этот процент в России все еще выше, чем показатель по миру в целом (2\%) [6].

\$100тыс-\$1млн - самый распространенный размер ущерба от экономических преступлений среди российских компаний (таблица 2).

\section{Анализ финансовых потерь от экономических преступлений за 2014 год, \%}

Таблица 2

\begin{tabular}{|l|l|l|l|}
\hline № & Размер ущерба финансовых потерь & по всему миру & по России \\
\hline 1 & финансовые потери в размере менее 50000 долларов США & 32 & 21 \\
\hline 2 & финансовые потери в размере 50000 - 100000 долларов США & 15 & 7 \\
\hline 3 & финансовые потери в размере 100000 - 1 млн. долларов США & 26 & 30 \\
\hline 4 & финансовые потери в размере 1 млн. - 5 млн. долларов США & 12 & 16 \\
\hline 5 & финансовые потери в размере 5 млн. - 100 млн. долларов США & 6 & 13 \\
\hline 6 & финансовые потери в размере свыше 100 млн. долларов США & 2 & 3 \\
\hline
\end{tabular}

Bсе вышесказанное позволило выявить наиболее характерные способы мошенничества. Как следствие, негативное восприятие и влияние на моральный климат, в случае совершения

ISPC European Technology in Science, противоправных действий, проявляются более ощутимо.

Несмотря на позитивные тенденции, российские компании по-прежнему сталкиваются с проблемами взяточничества и коррупции. По
Malmö, Sweden 
признанию 41\% респондентов, за последние два года их компаниям предлагалось дать взятку. Этот результат существенно выше, чем показатели в целом по миру $(18 \%)$ и по Восточной Европе (23\%). Примерно столько же респондентов (42\%; в целом по миру - 22\%) заявили, что упустили коммерческую возможность, проиграв конкуренту, который, по их мнению, дал взятку [6].

По мнению российского бизнес-сообщества «финансовые потери» являются самым серьезным последствием взяточничества и коррупции, (28\%). «Ущерб репутации»- самое значимое последствие взяточничества и коррупции по мнению руководителей во всем мире $(36 \%)$. Стоит отметить, что российские компании не считают ущерб деловой репутации самым серьезным последствием, как считают в других странах (в России - 19\%, в мире в целом $36 \%$, в Восточной Европе - 34\%) [6].

В случае совершения правонарушения внешними мошенниками самые популярные методы реагирования в России - это прекращение деловых отношений $(70 \%$, что значительно больше, чем в 2011 году), предъявление гражданских исков, в том числе с целью возмещения ущерба (60\%), и информирование правоохранительных органов (60\%). Любопытен тот факт, что прекращение деловых отношений во всем мире (37\%) или в Восточной Европе $(50 \%)$ не пользуется такой популярностью, как в России $(70 \%)$. Это означает, что российские компании хотят «начать с чистого листа», даже если конфликт урегулирован, а ущерб возмещен.

Каким образом может совершаться мошенничество с финансовой отчетностью?

Несмотря на то, что по результатам статистических исследований на мировых рынках (в том числе и в России) искажения финансовой отчетности представляются несколько меньшей угрозой, чем другие виды мошенничеств (незаконное присвоение активов и коррупция), наибольший негативный эффект компаниям может принести именно мошенничество с финансовой отчетностью.

Однако такая удручающая статистика вовсе не означает, что мошенничество в финансовой отчетности нельзя обнаружить. Для того чтобы решить данную проблему на развивающихся рынках, следует обратиться к опыту развитых стран, которые обладают значительной статистикой различных случаев мошенничества.

Ниже приведенной схеме представлены традиционные способы совершения мошенничества (рис.1):

\begin{tabular}{|c|c|c|c|c|}
\hline \multicolumn{5}{|c|}{ Способы совершения мошенничество с финансовой отчетностью } \\
\hline$\downarrow$ & $\downarrow$ & $\downarrow$ & $\downarrow$ & $\downarrow$ \\
\hline $\begin{array}{l}\text { Фиктивная } \\
\text { выручка }\end{array}$ & $\begin{array}{l}\text { Различия во времени } \\
\text { признания дохода или } \\
\text { расхода }\end{array}$ & $\begin{array}{l}\text { Неверная } \\
\text { оценка } \\
\text { активов }\end{array}$ & $\begin{array}{l}\text { Непризнание } \\
\text { обязательств } \\
\text { и расходов }\end{array}$ & $\begin{array}{l}\text { Недостоверное } \\
\text { или неполное } \\
\text { раскрытие } \\
\text { информации }\end{array}$ \\
\hline$\downarrow$ & $\downarrow$ & $\downarrow$ & $\downarrow$ & $\downarrow$ \\
\hline $\begin{array}{l}\text { заключается } \\
\text { в том, что в } \\
\text { бухгалтерско } \\
\text { м учете } \\
\text { отражаются } \\
\text { продажи, } \\
\text { которые } \\
\text { никогда не } \\
\text { имели место }\end{array}$ & \begin{tabular}{lr}
\multicolumn{3}{l}{ заключается } & в \\
скрытии плохих \\
показателей \\
одного \\
отчетных \\
периодов, \\
отражает доходы и \\
расходы \\
периоде, \\
котором том \\
выгоднее для них \\
\end{tabular} & $\begin{array}{l}\text { заключается в } \\
\text { том, что с } \\
\text { целью } \\
\text { манипулирован } \\
\text { ия уяовнем } \\
\text { прибыли } \\
\text { стоимость } \\
\text { имущества } \\
\text { компании } \\
\text { завышается } \\
\text { или занижается }\end{array}$ & $\begin{array}{l}\text { заключается } \\
\text { в } \\
\text { неотражении } \\
\text { или неполном } \\
\text { отражении в } \\
\text { учете } \\
\text { расходов и } \\
\text { обязательств } \\
\text { компании }\end{array}$ & $\begin{array}{l}\text { заключается в } \\
\text { манипулировани } \\
\text { и данными } \\
\text { отчетности. Это } \\
\text { происходит } \\
\text { после того, как } \\
\text { мошенничество } \\
\text { было совершено } \\
\text { и необходимо } \\
\text { его скрыть }\end{array}$ \\
\hline
\end{tabular}

Рисунок 1 - Классификация видов мошенничества

Выявление мошенничества с финансовой отчетностью основано на двух принципах:

- понимание того, что является нормой для того или иного бизнес-процесса (закупки, продажи, производство, финансы и т.д.), то есть как оно должно быть. К сожалению, сотрудники, отвечающие за обнаружение мошенничества, часто просто не знают, что является нормой. Поэтому многие мошенничества остаются невыявленными.

- поиск аномалий, то есть отклонений от нормы. Хотя не все аномалии свидетельствуют о 
мошенничестве, а в любом мошенничестве присутствуют аномалии. Если аномалия обнаружена, необходимо более детально изучить причины ее возникновения.

MCA 240 «Ответственность аудитора по рассмотрению мошенничества при аудите финансовой отчетности» предлагает два вида аналитических процедур, которые позволяют обнаружить мошенничество в финансовой отчетности [8]:

- рассмотрение финансовой информации компании в сравнении с информацией за прошлые периоды, с плановыми значениями, с данными по отрасли.

- рассмотрение взаимосвязей между элементами финансовой информации (например, показатели валовой прибыли), а также между элементами финансовой и нефинансовой информации (например, между расходами на оплату труда и численностью работников).

Первый способ называются горизонтальным анализом, рассмотрение взаимосвязей - это вертикальный анализ и расчет коэффициентов [9].

Горизонтальный анализ - это самый простой способ анализа финансовой отчетности. Его суть состоит в расчете процента изменения определенных финансовых показателей из года в год. При этом первый год принимается за базовый, и далее процент изменения показателя рассчитывается по отношению к базовому году. Такой анализ позволяет уловить тренд в изменении различных показателей, к примеру, в расходах на строительство или в выпуске продукции. Значительное необычное изменение, скажем, расходов на строительство может свидетельствовать о том, что с ними что-то не в порядке. Это может оказаться как результатом арифметической ошибки, так и преднамеренного искажения расходов. В любом случае дальше придется выяснять причины.

Вертикальный анализ также довольно распространен. Его суть заключается в рассмотрении взаимосвязей между отдельными показателями баланса, отчета о прибылях и убытках, отчета о движении денежных средств, выраженных в процентах. Например, при анализе показателей отчета о прибылях и убытках выручка принимается за $100 \%$, а остальные показатели рассчитываются как процент от этого показателя. Скажем, если вы замечаете, что доля коммерческих расходов в выручке значительно уменьшилась по сравнению с прошлыми периодами, это повод задуматься о том, нет ли там мошенничества.

И при вертикальном, и при горизонтальном анализе важно рассматривать показатели в динамике за несколько лет. Но следует иметь в виду, что с помощью этих видов анализа можно обнаружить только крупное мошенничество. Мелкое, регулярно совершаемое мошенничество с помощью этих методов не выявить. Расчет коэффициентов представляет собой отношение между показателями различных отчетов финансовой отчетности. Однако простой расчет коэффициентов может ничего не дать, если не понимать, каким образом мошенничество может проявиться в результатах расчета.

Одним из действенных показателей, который используется специалистами для обнаружения признаков мошенничества с финансовой отчетностью, был предложен профессором Kelly School of Business Мессодом Бенишем в 1999 году. Мессод Бениш, проанализировав финансовую информацию компаний, которые манипулировали и не манипулировали показателями своей отчетности, рассчитал восемь коэффициентов. Он включил эти коэффициенты с определенным весом в уравнение, которое было названо M-score Бениша [10]. Значение уравнения должно быть больше 2.22, чтобы считать, что компания имеет признаки мошенничества.

Значения рассчитанных коэффициентов подставляются в уравнение M-score:

$$
\begin{aligned}
& M=-4,84+0,92 * D S R I+0,528 * G M I+ \\
& +0,404 * A Q I+0,892 * S G I+0,115 * D E P I- \\
& -0,172 * S G A I+4,679 * T A T A-0,327 * L V G I
\end{aligned}
$$

где DSRI - индекс оборачиваемости дебиторской задолженности в днях;

GMI - индекс валовой маржи;

AQI - индекс качества активов;

SGI - индекс роста выручки;

DEPI - индекс амортизации;

SGAI - индекс коммерческих и управленческих расходов;

TAТА - суммарные начисления к суммарным активам;

LVGI - индекс финансового рычага.

Коэффициенты, которые участвуют в этой формуле рассчитываются следующим образом:

1) DSRI (Days' Sales in Receivables Index индекс оборачиваемости дебиторской задолженности в днях) рассчитывается как отношение дебиторской задолженности к выручке текущего года к отношению дебиторской задолженности к выручке прошлого года:

$$
D S R I=\frac{\left(Д 3_{t} / B P_{t}\right)}{\left(Д 3_{t-1} / B P_{t-1}\right)}
$$


Существенное увеличение этого показателя может свидетельствовать о фиктивных продажах.

2) GMI (Gross Margin Index - индекс валовой маржи) рассчитывается как отношение валовой маржи предыдущего года к валовой марже текущего года:

$$
G M I=\frac{\left(\left(B P_{t-1}-C / c_{t-1}\right) / B P_{t-1}\right)}{\left(B P_{t}-C / c_{t}\right) / B P_{t}}
$$

Когда значение этого индекса больше 1, это означает, что валовая маржа ухудшилась.

3) AQI (Asset Quality Index - индекс качества активов) рассчитывается как отношение качества активов текущего года к показателю предыдущего года:

$$
A Q I=\frac{\left(1-\left(\left(O б A_{t}+4 C O C_{t}\right) / \sum A_{t}\right)\right)}{\left(1-\left(O б A_{t-1}+4 C O C_{t-1}\right) / \sum A_{t-1}\right)}
$$

Чистая стоимость основных средств (ЧСОС) - это первоначальная стоимость основных средств за минусом накопленной амортизации.

4) SGI (Sales Growth Index - индекс роста выручки) рассчитывается как отношение выручки текущего года к выручке прошлого года:

$$
S G I=\frac{B P_{t}}{B P_{t-1}}
$$

Выручки не является показателем манипуляций, однако в стадии роста компании находятся под определенным давлением, которое может заставить их прибегнуть к фальсификации показателей.

5) DEPI (Depreciation Index - индекс амортизации) рассчитывается как соотношение нормы амортизации предыдущего года к норме амортизации текущего года:

$$
D E P I=\frac{\left(A m-я_{t-1} / \Pi C O C_{t-2}\right)}{\left(A m-я_{t} / \Pi C O C_{t-1}\right)} .
$$

Индекс амортизации больше 1 означает, что основные средства амортизируются медленнее, то есть расходы текущего периода на амортизацию уменьшаются. Это может быть признаком пересмотра норм амортизации с целью влияния на уровень чистой прибыли в сторону ее увеличения.

6) SGAI (Sales, General and Administrative expenses Index - индекс коммерческих и управленческих расходов) рассчитывается как отношение суммы коммерческих и управленческих расходов текущего года к этим же расходам предыдущего года:

$$
S G A I=\frac{\left(K P_{t}+y P_{t}\right)}{\left(K P_{t-1}+Y P_{t-1}\right)}
$$

7) TATA (Total Accruals to Total Assets суммарные начисления к суммарным активам) рассчитывается как отношение суммарных начислений к суммарным активам:

$$
T A T A=\frac{(\Delta O б A-\Delta K O-\Delta Д C-\Delta H У-A m-я)}{\sum A} .(8)
$$

Суммарные начисления рассчитываются как изменение в рабочем капитале (за исключением денежных средств) минус амортизация. Рабочий капитал рассчитывается как разница между оборотными активами и краткосрочными обязательствами.

8) LVGI (Leverage Index - индекс финансового рычага) рассчитывается как отношение кредитов и займов к суммарным активам текущего года к отношению кредитов и займов к суммарным активам предыдущего года:

$$
L V G I=\frac{\left(K 3_{t} / \sum A_{t}\right)}{\left(K 3_{t-1} / \sum A_{t-1}\right)} .
$$

Значение коэффициента больше 1 означает увеличение финансового рычага.

Исследуя реальное состояние компании, первоначальные данные о фальсификации финансовой отчетности удалось бы получить с помощью расчета коэффициентов Бениша. Использование горизонтального и вертикального анализа в совокупности с расчетом коэффициентов Бениша в большинстве случаев позволяет обнаружить индикаторы мошенничества. Но следует помнить, что индикаторы мошенничества - это еще не доказательство мошенничества, поэтому за обнаружением индикаторов всегда должна идти детальная работа по выяснению причин отклонения от нормы.

В заключение хотелось бы отметить, что потери от мошеннических действий могут быть существенными, потому что вероятность обнаружения невелика, хотя мошенникам риска больше потерять работу, но во многих случаях они остаются безнаказанными. Многие руководители не хотят аффишировать мошеннические действия своих сотрудников, в основном только прекращая трудовые отношения. 
Актуальным проблемам совершенствования аналитических процедур для оценки финансовой информации относят: во-первых, отставание отечественной нормативно-правовой базы, регулирующей применение аналитических процедур в финансовых расследованиях, от международной практики нормативного регулирования. Во-вторых, отсутствием в практике достаточного количества надлежащих методических руководств по применению аналитических процедур для этой цели. Таким образом, понятия форензик и мошенничество сложные, безусловно требующие научного исследования.

\section{References:}

1. (2010) Forensic science in court: challenges in the 21st century. Shelton, T. 2010. Electronic book.

2. Wielbo D (2000) HISTORY / Forensic Sciences, In: Editor-in-Chief: Jay A. Siegel, Editor(s)-in-Chief, Encyclopedia of Forensic Sciences, Elsevier, Oxford, 2000, - pp. 10701075.

1. (2015) Tolkovyy slovar' zhivogo velikorusskogo yazyka. Available: https://slovari.yandex.ru/ (Accessed: 10.02.2015).

2. Sunchalieva LE (2004) Moshennichestvo (ugolovno-pravovoy i kriminologicheskiy aspekt). Diss. kand. yurid. nauk. - Stavropol', 2004.

3. (2007) Postanovlenie Plenuma Verkhovnogo Suda RF ot 27.12.2007 N 51 «O sudebnoy praktike po delam o moshennichestve, prisvoenii i rastrate» (rus.). lawmix.ru (27 dec 2007). Provereno 2 november 2012. Arkhivirovano iz pervoistochnika 7 nov 2012.

4. (2014) Vsemirnyy obzor ekonomicheskikh prestupleniy - 2014. Available: http://www.pwc.ru/ (Accessed: 02.02.2015).
5. (2011) Vsemirnyy obzor ekonomicheskikh prestupleniy - 2011. Available: http://www.pwc.ru/ (Accessed: 10.02.2015).

6. (2015) MSA 240 «Otvetstvennost' auditora po rassmotreniyu moshennichestva pri audite finansovoy otchetnosti». Available: http://www.cfin.ru/ias/msfo/review.shtml (Accessed: 10.02.2015).

7. Sheremet AD, Negashev EV (2013) Metodika finansovogo analiza deyatel'nosti kommercheskikh predpriyatiy. - 2-e izd. Moscow: INFRA-M, 2013.- 360p.

8. Warshavsky M (2012) Analyzing Earnings Quality as a Financial Forensic Tool. forensics/fraud - earnings Quality and the Beneish Model october/november 2012. pp. 1620 Available: www.gettrymarcus.com/.../Analyzing-Earnings (Accessed: 10.02.2015). 